We propose that the susceptibility to nephropathy in insulin dependent diabetics is linked with the liability to raised arterial pressure. This predisposition, as manifested in the parents, is likely to be transmitted genetically, ${ }^{24}$ though mediation through familial sharing of environmental factors cannot totally be excluded..$^{28}$ Interestingly, comparatively low blood pressure is an almost universal feature among long term survivors of uncomplicated diabetes. ${ }^{29}$

We thank Mr T Murrells and Mr F House for statistical advice, Mrs J Gray for secretarial help, and the British Diabetic Association for research group support.

\section{References}

1 Andersen AR, Christiansen JS, Andersen JK, Kreiner S, Deckert T. Diabetic nephropathy in type I (insulin dependent) diabetes: an epidemiological study. Diabetologia 1983;25:496-501.

2 Krolewski A, Warram JH, Christlieb AR, Bunsick EJ, Kahn CR. The changing natural history of nephropathy in type I diabetes. Am $\mathcal{F}$ Med 1985;78:785-94.

3 Pirart J. Diabete et complications degeneratives: presentation d'une etude prospective portant sur 4,400 cas observe entre 1947 et 1973. Diabete Metab 1977;3:97-107, 173-82, 245-56.

4 Deckert T, Poulsen JE. Diabetic nephropathy: fault or destiny? Diabetologia 1981;21:178-83.

5 Mauer SM, Steffes MW, Ellis EN, Sutherland DER, Brown DM, Goetz FC. Structuralfunctional relationships in diabetic nephropathy. $\mathcal{F}$ Clin Invest 1984;74:1143-55.

6 Barnett A, Mijovic C, Fletcher J, et al. Low plasma C4 concentrations: association with microangiopathy in insulin-dependent diabetes. BrMed 7 1984;289:943-5.

7 Mijovic C, Fletcher JA, Bradwell AR, Barnett AH. Phenotypes of the heavy chains of immunoglobulins in patients with diabetic microangiopathy: evidence for an immunogenetic pre-disposition. BrMed J 1986;292:433-5.

8 Cooper ME, Duff R, Buchman R, McPherson J, Jerums G. Low serum C4 concentrations and microangiopathy in type I and type II diabetes. Br Med $\mathcal{f}$ 1986;292:301.

9 Cudworth AG, Bodansky HJ. Genetic and immunological factors in diabetic complications. In: Keen H, Jarrett RJ, eds. Complications of diabetes. 2nd ed. London: Edward Arnold, 1982:1-12.
10 Parving HH, Smidt UM, Frisberg B, Bonnevie-Nielsen V, Andersen AR. A prospective study of glomerular filtration rate and arterial blood pressure in insulin-dependent diabetics with diabetic nephropathy. Diabetologia 1981;20:457-61.

11 Drury PL. Diabetes and arterial hypertension. Diabetologia 1983;24:1-9.

12 Keen H, Track NS, Sowry GSC. Arterial pressure in clinically apparent diabetics. Diabete Metab 1975;1:159-78.

13 Wiseman MJ, Viberti GC, Mackintosh D, Jarrett RJ, Keen H. Glycaemia, arterial pressure and microalbuminuria in type I (insulin-dependent) diabetes mellitus. Diabetologia 1984;26:401-5. 14 Mathiesen ER, Oxenboll D, Johansen K, Svendsen PA, Deckert T. Incipient nephropathy in type I insulin-dependent diabetes. Diabetologia 1984;26:406-10.

15 Mogensen CE, Christensen CK. Predicting diabetic nephropathy in insulin-dependent patients. N Engl f Med 1984;311:89-93.

16 Viberti GC, Hill RD, Jarrett RJ, Argyropoulos A, Mahmud U, Keen H. Microalbuminuria as a predictor of clinical nephropathy in insulin-dependent diabetes mellitus. Lancet 1982;i:1430-2. 17 Pickering GW. High blood pressure. 2nd ed. London: J \& A Churchill, 1968:236-73.

18 Black DAK, Cameron JS. Renal function. In: Brown SS, Mitchell PL, Young DS, eds. Chemical diagnosis of disease. Amsterdam: Elsevier, 1979:453-524.

19 Cox DR. Analysis of binary data. London: Methuen \& $\mathrm{Co}, 1970$.

20 Thomsen AC. The kidney in diabetes mellitus. Copenhagen: Munksgaard, 1965. (Thesis.)

21 Bianchi G, Cusi D, Guidi E. Renal hemodynamics in human subjects and in animals with genetic hypertension during the pre-hypertensive stage. Am $\mathcal{F}$ Nephrol 1983;3:3-79.

22 Sandahl-Christiansen J, Gammelgaard J, Frandsen M, Parving HH. Increased kidney size, glomerular filtration rate and renal plasma flow in short-term insulin-dependent diabetics. Diabetologia 1981;20:451-6.

23 Thomsen OF, Andersen AR, Christiansen JS, Deckert T. Renal changes in type I (insulindependent) diabetic patients with and without clinical nephropathy: a light microscopic, dependent) diabetic patients with and without clinical nephropathy:

morphometric study of autopsy material. Diabetologia 1984;26:361-5.
24 Hilton PJ. Cellular sodium transport in essential hypertension. N Engl f Med 1986;314:222-9.

24 Hilton PJ. Cellular sodium transport in essential hypertension. $N$ Engl J Med 1986;314:222-9.
25 Mangili M, Bending JJ, Scott G, Li LK, Gupta A, Viberti GC. A marker for diabetic Mangili M, Bending JJ, Scott G, Li LK, Gupta A, Viberti GC. A marker for diabetic
nephropathy. Increased red cell $\mathrm{Na}^{+} / \mathrm{Li}^{+}$exchanger activity. Diabetes 1987;36 (suppl 1):43A.

26 Krolewski A, Rand L, Canessa M, Phillips L. Genetic predisposition to hypertension is a risk factor for renal but not eye complications in IDD. Diabetes 1987;36(suppl 1):106A

27 Mauer SM, Steffes MW, Azar S, Sandberg SK, Brown DM. The effects of Goldblatt hypertension on development of the glomerular lesions of diabetes mellitus in the rat. Diabetes 1978;27:738-44.

28 Speers MA, Kasl SV, Freeman DH, Ostfeld AM. Blood pressure concordance between spouses. Am f Epidemiol 1986;23:818-29.

29 Borch-Johnsen K, Nissen RN, Nerup J. Blood pressure after 40 years of insulin-dependent diabetes. Diabetic Nephropathy 1985;4:11-2.

(Accepted 29 fune 1987)

\title{
Controlled multicentre therapeutic trial of an unrefined carbohydrate, fibre rich diet in Crohn's disease
}

\author{
JEAN K RITCHIE，JANE WADSWORTH， J E LENNARD-JONES， ELIZABETH ROGERS
}

\begin{abstract}
Between 1 September 1980 and 31 August 1983, 352 patients with inactive or mildly active Crohn's disease but not taking drug treatment apart from sulphasalazine were entered from 40 hospitals into a prospective trial to assess the effects of two different diets on disease activity over two years. One hundred and sixty two patients were randomly allocated to take a diet unrestricted in sugar and low in fibre and 190 to a diet with little or no sugar and high in unrefined carbohydrate.

No clear difference in clinical course was detected among patients who accepted the two different types of dietary advice.
\end{abstract}

\section{St Mark's Hospital, London EC1V 2PS}

JEAN K RITCHIE, DM, MRCP, senior research fellow

J E LENNARD-JONES, MD, FRCP, consultant gastroenterologist

Academic Department of Community Medicine, St Mary's Hospital Medical School, London

JANE WADSWORTH, MSC, lecturer in medical statistics

St Bartholomew's Hospital, London

ELIZABETH ROGERS, BSC, SRD, chief dietitian

Correspondence to: Professor Lennard-Jones, St Mark's Hospital.

\section{Introduction}

One of the most difficult features of Crohn's disease is its chronicity and tendency to recur after resection. A harmless treatment which decreased the relapse rate after medical or surgical treatment would represent real progress. Many studies have shown that patients with Crohn's disease tend to eat more sugar,,$^{1-8}$ and one study also showed less raw fruit and vegetables, ${ }^{4}$ than healthy control subjects. A retrospective comparison suggested that the clinical course of 32 patients treated with a diet low in refined carbohydrate and high in unrefined cereals, vegetables, and fruit was more favourable than that of a matched group of patients treated without dietary modification. ${ }^{9}$

We report the results of a randomised prospective single blind trial over two years of two types of dietary advice given to patients with Crohn's disease who were well despite the presence of diseased intestine or after resection. One group of patients was advised to avoid refined carbohydrate and to replace it with unrefined carbohydrate. This change resulted in increased dietary fibre but a fibre supplement was not advised. The other group was advised to avoid unrefined cereal foods but was given no advice to alter the consumption of refined carbohydrate.

\section{Patients and methods}

Selection of patients-Criteria for the diagnosis of Crohn's disease were based on a typical clinical history with characteristic appearances in radiographs or at laparotomy and whenever possible confirmed by biopsy or 
a resection specimen. Patients with a stoma and those with disease limited to the stomach or duodenum, or both, were excluded, as were patients with anal disease only. From among patients attending their outpatient clinics participating clinicians were asked to identify patients with Crohn's disease who were well, either with known structural disease or after resection of all apparently diseased intestine, and who were receiving no treatment other than nutritional supplements, antidiarrhoeal drugs, or maintenance sulphasalazine. Clinicians were asked to invite such patients to enter a trial of two types of diet to assess whether recurrence of disease activity was affected by the type of food eaten.

Assessment of outcome-The object of the trial was to assess the proportion of patients in each trial group who had a relapse of their disease. Clinical deterioration was defined in order of decreasing importance as the need for surgical or medical treatment in hospital; need for corticosteroid, sulphasalazine (if not already being taken), antibiotic, or immunosuppressive drug treatment for intestinal disease as an outpatient; or as a worsening of symptoms attributable to the disease and severe enough to warrant withdrawal from the trial. Each of these events constituted an "end point" and was regarded as failure of dietary advice to prevent deterioration of disease. Some patients also left the trial because they did not wish to continue one or other of the diets advised, either because they did not like it or because they considered that it caused symptoms. These patients were distinguished from those who left the trial for unrelated or unknown reasons. Patients who completed two years in the trial were those in whom there was no evident clinical deterioration. Their wellbeing at the beginning and end of the trial was assessed in terms of symptoms, body weight, and laboratory findings.

Power of trial-At the outset we estimated that about $40 \%$ of patients with Crohn's disease who are well develop recurrent symptoms requiring treatment within two years. ${ }^{10} 11$ To detect a halving of this rate in nine out of 10 trials 260 patients should be studied for up to two years. ${ }^{12}$ In the event, clinicians from 40 hospitals collaborated to enable 352 patients to be included.

Randomisation and "blindness"-Eligible patients were invited to enter the trial after full explanation by the clinician. Those who accepted were referred to the dietitian, who held the randomisation code as a consecutive series of sealed envelopes. A further explanation of the principles of each diet was given by the dietitian, and if the patient agreed to accept whichever of the two diets was allocated the next envelope was opened and the trial diet disclosed. The clinician was not informed of the diet allocated and, as far as possible, remained blind to the advice given.

Dietary advice-Patients in dietary group A were advised to eat carbohydrate in its refined form using white flour and rice and to avoid unrefined carbohydrate foods; sugar intake was unrestricted. Patients in dietary group B were advised to eat carbohydrate in its natural unrefined state only, avoiding all products containing sugar or white flour; this diet was the same as that advocated in the Bristol study.' Both types of advice were accompanied by a booklet, modelled on that used in Bristol, which explained the principles of the diet and gave a list of "acceptable" and "unacceptable" foods. At every visit the dietitian reviewed the patient's diet and strongly reinforced the advice given.

Dietary assessment-At entry to the trial and every six months thereafter the patient's sugar and fibre intake was assessed by the dietitian using a standard form and a special list of common foods and household measures based on the tables of McCance and Widdowson, ${ }^{13}$ supplemented by manufacturers' data. Assessment was by the recall method. Patients were encouraged to keep a diary of food.eaten on one weekday and one day at the weekend using prepared forms as examples of their diet.

TABLE I-State and comparability of treatment groups at entry to trial. Except where stated otherwise values are medians (ranges in parentheses)

\begin{tabular}{lcc}
\hline & $\begin{array}{c}\text { Dietary group A } \\
(\mathbf{n}=162)\end{array}$ & $\begin{array}{c}\text { Dietary group B } \\
(\mathbf{n}=190)\end{array}$ \\
\hline Sex: & & \\
No (\%) male & $60(37 \cdot 0)$ & $70(36 \cdot 8)$ \\
No (\%) female & $102(63 \cdot 0)$ & $120(63 \cdot 2)$ \\
Age (years) & $35 \cdot 6(15 \cdot 5 \cdot 68 \cdot 6)$ & $35 \cdot 2(14 \cdot 4-77 \cdot 7)$ \\
Weight (kg) & $60(39-94)$ & $60(41-102)$ \\
Haemoglobin (g/l) & $133(91-169)$ & $133(84-171)$ \\
Erythrocyte sedimentation rate (mm in first hour) & $10(1-63)$ & $12(1-140)$ \\
No(\%) taking sulphasalazine at entry & $35(21 \cdot 6)$ & $29(15 \cdot 3)$ \\
No(\%) with structural disease present & $104(64 \cdot 2)$ & $114(60 \cdot 0)$ \\
No with previous resection, recurrence & 31 & 27 \\
No with no previous resection & 73 & 87 \\
Site: & 31 & 37 \\
$\quad$ Small bowel & 18 & 19 \\
Small and large bowels & 24 & 31 \\
Large bowel & & $76(40 \cdot 0)$ \\
No(\%) with no macroscopic disease after resection & $58(35 \cdot 8)$ & \\
& & \\
\hline
\end{tabular}
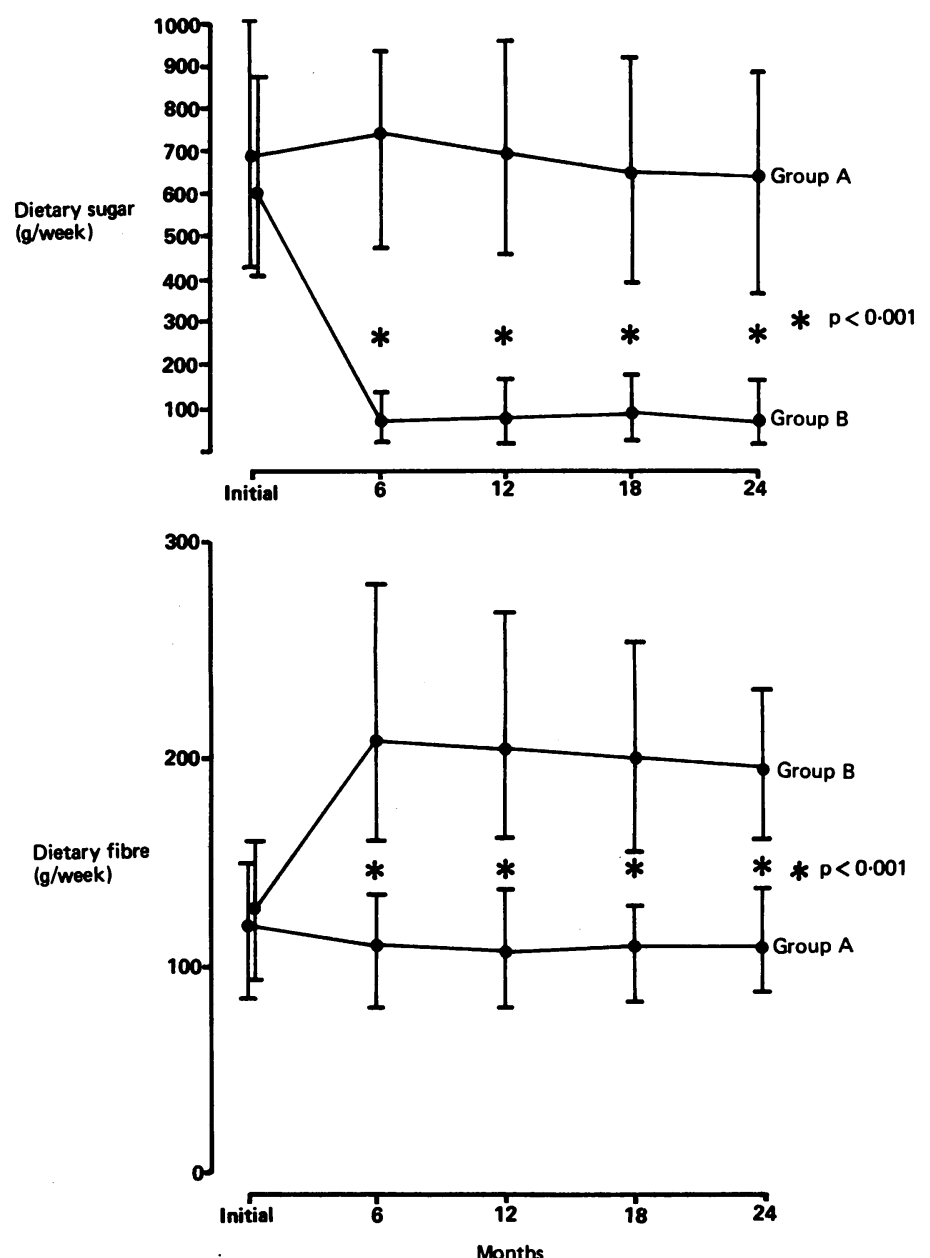

FIG 1-Reportcd sugar and tibre consumption at beginning of trial and at six month intervals during trial in the two dietary groups using all available data. Results shown as median intakes with interquartile ranges.

Clinical assessment-A detailed form giving the previous history, diagnostic criteria, symptoms, body weight, height, and laboratory data was completed at entry. Thereafter a clinical assessment form was completed every three months to give changes in treatment, the data needed to calculate a simple clinical index,$^{14}$ and laboratory findings.

Administration-All clinical and dietary assessment forms were sent to $\mathrm{St}$ Mark's Hospital and checked by the administrator (JKR) and a dietitian (ER) respectively. Queries were dealt with by letter.

Statistical analysis-Non-parametric statistics were used throughout. Results for continuously distributed variables were expressed as median and interquartile range- that is, the range of values lying between the 25 th and 75 th centiles - and the significance of differences between patients in dietary groups $A$ and $B$ assessed by the Mann-Whitney $U$ test. ${ }^{15}$ Other results were expressed as proportions and the log rank test used to compare survival curves of subjects taking the two diets remaining in the trial. ${ }^{16}$ For clarity in the figures only the final standard errors (SE) of surviving proportions are shown.

\section{Results}

Three hundred and fifty two patients were entered into the trial; 162 were randomised to dietary group A and 190 to dietary group B. It was not possible to define the total populations of eligible patients from whom the sample was drawn. At entry the patients assigned to the two dietary groups were very similar with regard to age, sex, and clinical state (table I).

The median sugar intake in the two study groups at entry was $689 \mathrm{~g} /$ week (range 85-2180 g) in group A and $614 \mathrm{~g} /$ week $(25-2072 \mathrm{~g}$ ) in group B. For patients who completed the trial the figures were $644 \mathrm{~g} /$ week (group A) and $63 \mathrm{~g} /$ week (group B). The median fibre consumption at entry was $120 \mathrm{~g} /$ week (range 38-304 g) for patients in group $A$ and $127 \mathrm{~g} /$ week (44-518 $\mathrm{g}$ ) for those in group B. At the end of two years the figures were $110 \mathrm{~g} /$ week and $195 \mathrm{~g} /$ week respectively. Figure 1 shows the median and interquartile ranges 
for sugar and fibre consumption based on all available dietary assessments; there was good compliance with the two diets.

The trial was designed to last two years and 178 patients completed it. The remaining 174 patients required treatment or withdrew for various reasons. Table II summarises the results based on the intention to treat. Twenty one patients were treated surgically during the trial, 14 in dietary group A and seven in dietary group B. The operations were right hemicolectomy in 11 patients (group A six, group B five), resection of anastomosis in seven (A five, B two), stricturoplasty in one (A), and ileostomy in two (A). Though operative treatment was more common in patients in group $A$, the difference was of marginal significance $\left(\chi^{2}=2 \cdot 998 ; 0 \cdot 10>p>0 \cdot 05\right)$.

TABLE II-Clinical outcome in the two treatment groups. Figures are numbers (percentages) of patients

\begin{tabular}{lcc}
\hline & $\begin{array}{c}\text { Dietary group A } \\
(\mathbf{n}=162)\end{array}$ & $\begin{array}{c}\text { Dietary group B } \\
(\mathbf{n}=190)\end{array}$ \\
\hline $\begin{array}{l}\text { End points: } \\
\text { Intestinal surgery }\end{array}$ & $14(8 \cdot 6)$ & $7(3 \cdot 7)^{\star}$ \\
$\begin{array}{l}\text { Hospital admission } \\
\text { Withdrawal, more symptoms }\end{array}$ & $\begin{array}{r}(13 \cdot 0) \\
2(1 \cdot 2)\end{array}$ & $\begin{array}{c}18(9 \cdot 5) \\
20(10 \cdot 5)\end{array}$ \\
Outpatient treatment & $15(9 \cdot 3)$ & $21(11 \cdot 1)$ \\
\hline Total & $52(32 \cdot 1)$ & $66(34 \cdot 7)$ \\
\hline Other withdrawals: & $4(2 \cdot 5)$ & $20(10 \cdot 5)$ \\
$\quad$ Non-compliance & $8(4 \cdot 9)$ & $6(3 \cdot 2)$ \\
Unknown & $8(4 \cdot 9)$ & $10(5 \cdot 3)$ \\
\hline Unrelated & $20(12 \cdot 3)$ & $36(18 \cdot 9)$ \\
\hline Total & $24(14 \cdot 8)$ & $28(14 \cdot 7)$ \\
\hline Two years in trial: & $11(6 \cdot 8)$ & $1(0 \cdot 5)$ \\
Score worse & $55(34 \cdot 0)$ & $59(31 \cdot 1)$ \\
\hline Score unchanged & $90(55 \cdot 6)$ & $88(46 \cdot 3)$ \\
\hline Total & & \\
\hline
\end{tabular}

${ }^{\star} \chi^{2}=2 \cdot 998 ; p>0 \cdot 05$

Thirty nine patients were admitted to hospital during the two years, 21 in group $\mathbf{A}$ and 18 in group $\mathbf{B}$. Reasons for admission were acute relapse in seven cases (group A three, group B four), abdominal pain or small bowel obstruction in 18 (A 13, B five), complications of Crohn's disease in five (A one, $B$ four), investigation or assessment in two (A), and anal operations in seven (A two, $B$ five). Two patients allocated to diet $\mathbf{A}$ withdrew, as they considered that the diet led to increased diarrhoea. Twenty patients taking diet $\mathrm{B}$ reported an increase in symptoms (nine diarrhoea, seven loss of weight, four abdominal pain) and withdrew from the trial. Twenty other patients taking diet $\mathrm{B}$ and four taking diet $\mathrm{A}$ failed to attend for follow up. Other outcomes showed little difference between the diets.

Life table analysis was used to compare the progress of patients taking the two diets. Figure 2 shows the cumulative proportion of patients remaining in the trial without deterioration of the disease resulting in one of the end points listed in table II. The proportions at two years were $64 \%$ (SE $4 \%$ ) in group A and $59 \%(4 \%)$ in group $B$. The log rank test showed no significant difference between the diets. A similar method of analysis (fig 3) applied to patients withdrawing from the trial for any reason other than worsening symptoms (see table II) showed a significant difference $(p<0.03)$ between the diets at two years (8\% (SE 4\%) for diet A, 29\% (4\%) for diet B), with an excess of withdrawals from diet $\mathrm{B}$ at the beginning of the trial.

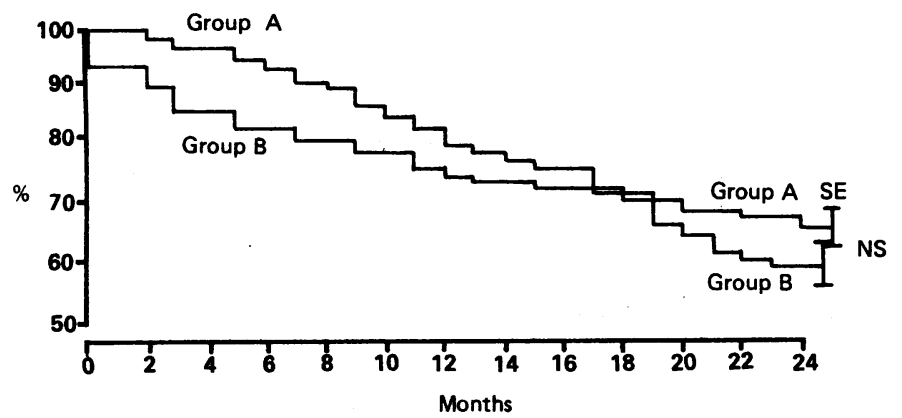

FIG 2-Percentage cumulative probability of deterioration of disease shown by reaching one of end points listed in table II during trial.

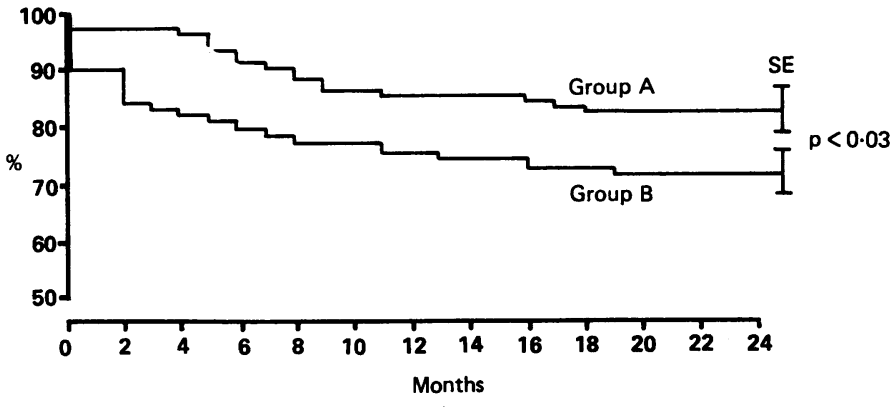

FIG 3-Percentage cumulative probability of withdrawal from trial for reasons other than deterioration of disease.

Patients who completed two years in the trial remained well. The clinical score, stool count, and body weight showed no significant change with either diet (table II).

Within the two dietary groups there was a wide variation in consumption of fibre and sugar. When the analysis was restricted to those patients who after six months of diet $\mathrm{A}$ reported sugar consumption above the upper quartile $(765 \mathrm{~g} /$ week) and fibre consumption below the lower quartile $(100 \mathrm{~g} /$ week) and to those taking diet $\mathrm{B}$ who reported sugar consumption below the lower quartile $(60 \mathrm{~g} /$ week $)$ and fibre consumption above the upper quartile $(205 \mathrm{~g} /$ week) the comparisons then referred to patients who complied very well with their dietary advice. When the analysis was restricted to these 24 patients taking diet $A$ and 38 taking diet $B$ there were no evident differences in outcome.

\section{Discussion}

Studies in Britain, Germany, Israel, and Sweden have all shown that patients with Crohn's disease tend to eat more sugar than do matched healthy controls. ${ }^{1-8}$ Such unanimity is unusual and offers one of the few clues about the aetiology or pathogenesis of the disease. All but one of these investigations used a method of dietary assessment based on interviews or postal questionnaires; in the only survey in which all items of diet over five days were weighed no significant differences were found, but there was a trend towards more added sugar among the patients than the controls. ${ }^{7}$ One controlled study estimated the preillness diet soon after diagnosis of Crohn's disease ${ }^{4}$ and another recorded both the diet reported by patients during the illness and their recall of what they had consumed in health. ${ }^{7}$ Comparison between sugar intake within six months of diagnosis in one group with the intake seven to 36 months after diagnosis in another showed that the intake of sugar tended to be greater with the longer history of disease and suggested that the increased intake of sugar was a secondary phenomenon. ${ }^{8}$

In this study the initial dietary assessments showed a median consumption of about $90 \mathrm{~g}$ sugar daily, similar to the median of $80 \mathrm{~g}$ in another study of Crohn's disease.$^{8}$ These figures are lower than the published mean daily intakes of $115-200 \mathrm{~g}$ in patients with Crohn's disease in other published studies and of the same order as the $91 \mathrm{~g}$ in men and $57 \mathrm{~g}$ in women measured by weighing among healthy Cambridgeshire villagers. ${ }^{17}$

The median fibre intake of $17-18 \mathrm{~g}$ daily found in the preliminary questionnaire in this trial was similar to that estimated by Thornton et al among patients with Crohn's disease before the onset of symptoms. ${ }^{4}$ Their dietary surveys naturally led to the suggestion that an alteration in diet might affect the clinical course of Crohn's disease. A retrospective study based on comparing the course of the disease among patients attending two different clinics, one of which advocated a low refined, high unrefined carbohydrate diet, suggested that this diet might be beneficial. Though efforts were made to match the groups, differences in selection and in other aspects of management may have affected the results. The only other prospective controlled trial of a low refined carbohydrate diet compared with a normal diet was limited to 20 patients but did suggest that reducing added sugar was helpful. ${ }^{18}$ An Italian trial found no difference in outcome between a low fibre (residue) diet and an unrestricted (normal fibre) diet. ${ }^{19}$ 
Our trial was planned in 1979; the first patient was entered in 1980 and the last patient completed the trial in 1985. Forty five clinicians from 40 hospitals collaborated. One hospital contributed 68 patients, 13 hospitals between 10 and 21 patients, and 26 hospitals fewer than 10 patients. It might be suggested that the dietary assessment method used was unreliable, particularly because patients wish to show their compliance with the advice given. Most patients appeared to make a sustained effort to alter their diet as advised. Even though the trial inevitably tested the advice given rather than known conformity to the diet, this is the situation in clinical practice.

It soon became apparent that some patients did not wish to continue the low refined, high unrefined carbohydrate diet. Some said that it made their symptoms worse, some that it caused weight loss, and others did not like it. About $10 \%$ of patients allocated to this diet withdrew for one of these reasons. Furthermore, a similar additional proportion of patients in this dietary group failed to attend for follow up, suggesting that more patients allocated to this diet than the other found the trial unacceptable in practice. Conversely, a few patients who normally took a high fibre diet but were allocated to take the diet low in fibre found this change difficult to tolerate.

The failure of this trial to show any convincing difference in the clinical course of the disease in the two treatment groups is disappointing. It might be argued that a therapeutic response would have been more likely among patients with active disease. The trial was not conducted among such patients because the response would be difficult to evaluate when drugs were being taken and because there is a real need to find a treatment which decreases the long term relapse rate in those with inactive disease. The cumulative probability of deterioration of the disease was similar to the $40 \%$ expected when planning the trial, but the actual proportion of patients who deteriorated resulting in the end points listed in table II was smaller (group A 32\%, group B 35\%). The difference between the groups was smaller than that judged clinically important when planning the trial. Even among the small group of patients who complied best with the advice given no difference was discernible; it seems unlikely that patients will alter their intake of sugar or dietary fibre, or both, to a greater extent than achieved by this group.

A high proportion of patients in whom all macroscopic disease is resected develop aphthoid ulcers at the anastomotic site within one year of operation..$^{20}$ Hence most of the 134 patients in this group (table I) probably had occult disease during the two years of the trial. The results suggest that both the course of mildly active Crohn's disease and deterioration after resection are unaffected by advising replacement of refined by unrefined carbohydrate in the diet. Whether a reduction in sugar intake without a concurrent increase in fibre intake would be beneficial cannot be determined from our study. Other reports have suggested that different dietary approaches may be beneficial, ${ }^{21}{ }^{22}$ but the results of large trials of these diets are awaited.

The following clinicians collaborated in the trial and we are very grateful both to them and to all the dietitians who took part:

Dr R N Allan, General Hospital, Birmingham; Dr A T R Axon, Leeds General Infirmary; Dr R E Barry, Bristol Royal Infirmary; Dr J R Bennett, Hull Royal Infirmary; Professor I A D Bouchier, Ninewells Hospital, Dundee; Dr H Brady, Sandwell District General Hospital, West Bromwich; Dr W R Burnham, Oldchurch Hospital, Romford; Dr A R Davidson, Kettering General Hospital; Dr E Elias, Queen Elizabeth Hospital, Birmingham; Professor I E Gillespie, Manchester Royal Infirmary; Dr S R Gould, Epsom District Hospital; Dr R F Harvey, Frenchay Hospital, Bristol; Mr P R Hawley, Mr C V Mann, Mr R J Nicholls, Mr J M A Northover, Mr J P S Thomson, and Mr I P Todd, St Mark's Hospital, London; Dr D J Holdstock, Ashford Hospital, Middlesex; Dr C D Holdsworth, Royal Hallamshire Hospital, Sheffield; Dr J Howel Jones, Walsgrave Hospital, Coventry; Dr J Hywel Jones, Singleton Hospital, Swansea; Dr G D Kerr, Royal Shrewsbury Hospital; Dr J D Kinloch, Chase Farm Hospital, Enfield; Mr R H S Lane, Royal Hampshire County Hospital, Winchester; Professor M J S Langman, City Hospital, Nottingham; Surgeon Commander R J Leicester, Royal Naval Hospital, Haslar; Dr A J Levi, Northwick Park Hospital, Harrow; Mr C G Marks, Royal Surrey County Hospital, Guildford; Dr W D W Rees and Professor L A Turnberg, Hope Hospital, Salford; Dr R I Russell and Dr D A Farah, Royal Infirmary, Glasgow; Dr K F R Schiller, St Peter's District General Hospital, Chertsey; Dr W Sircus, Western General Hospital, Edinburgh; Dr E T Swarbrick, New Cross Hospital,
Wolverhampton; Mr C W Venables, Freeman Hospital, Newcastle upon Tyne; Professor D G Weir, Sir Patrick Dun's Hospital, Dublin; Surgeon Commander J G Williams, Royal Naval Hospitals, Plymouth and Haslar; Dr C P Willoughby, Basildon Hospital, Essex; Dr J M T Willoughby, Lister Hospital, Stevenage; Professor R Wright, Southampton General Hospital; Dr G R Youngs, Chester Royal Infirmary; Dr R Zeegen, Westminster Hospital, London.

We also thank all the patients, who took part so willingly and conscientiously; Professor M J S Langman for helpful advice about the analysis of the results; and Mrs Penny Jarvis, Miss Dorabella Northcott, Miss Jane Brice, $\mathrm{Mr} \mathrm{M}$ Wheeler, and $\mathrm{Mr}$ A R Patterson for administration and clerical help. The trial was made possible by financial support from the British Digestive Foundation.

Copies of the complete protocol and of the clinical and dietary assessment forms used in the trial may be obtained from JKR.

\section{References}

1 Miller B, Fervers F, Rohbeck R, Strohmeyer G. Zuckerkonsum bei patienten mit morbus Crohn. Verh Dtsch Ges Inn Med 1976;82:922-4.

2 Martini GA, Brandes JW. Increased consumption of refined carbohydrates in patients with Crohn's disease. Klin Wochenschr 1976;54:367-71.

$3 \mathrm{Kasper} \mathrm{H}$, Sommer H. Dietary fiber and nutrient intake in Crohn's disease. Am $\mathcal{J}$ Clin Nutr 1979;32:1898-901.

4 Thornton JR, Emmett PM, Heaton KW. Diet and Crohn's disease: characteristics of the pre-illness diet. BrMed f 1979;ii:762-4.

5 Mayberry JF, Rhodes J, Newcombe RG. Increased sugar consumption in Crohn's disease. Digestion 1980;20:323-6.

6 Silkoff K, Hallak A, Yegena L, et al. Consumption of refined carbohydrate by patients with Crohn's disease in Tel-Aviv-Yafo. Postgrad Med F 1980;56:842-6.

7 Mayberry JF, Rhodes J, Allan R, et al. Diet in Crohn's disease. Two studies of current and previous habits in newly diagnosed patients. Dig Dis Sci 1981;26:444-8.

8 Jarnerot G, Jarnmark I, Nilsson K. Consumption of refined sugar by patients with Crohn's disease, ulcerative colitis or irritable bowel syndrome. Scand f Gastroenterol 1983;18:999-1002. 9 Heaton KW, Thornton JR, Emmett PM. Treatment of Crohn's disease with an unrefinedcarbohydrate, fibre-rich diet. $\mathrm{BrMed} \mathcal{F}$ 1979;ii:764-6.

10 Summers RW, Switz DM, Sessions JT, et al. National cooperative Crohn's disease study: results of drug treatment. Gastroenterology 1979;77:847-69.

11 Multicentre Trial Group. Sulphasalazine in asymptomatic Crohn's disease. Gut 1977;18:69-72.

12 Fleiss JL. Statistical methods for rates and proportions. New York: John Wiley, 1973.

13 Paul AA, Southgate DAT, eds. McCance and Widdowson's the composition of foods. London: HMSO, 1978.

4 Harvey RF, Bradshaw JM. A simple clinical index of Crohn's-disease activity. Lancet 1980;i:514.

5 Siegel S. Non-parametric statistics for the behavioral sciences. New York: McGraw-Hill, 1956: 116-27.

16 Peto R, Pike HC, Armitage P, et al. Design and analysis of randomized clinical trials requiring prolonged observation of each patient. II: Analysis and examples. Brf Cancer 1977;35:1-39.

17 Bingham S, McNeil NI, Cummings JH. The diet of individuals: a study of a randomly-chosen cross section of British adults in a Cambridgeshire village. Brf Nutr 1981;45:23-35.

18 Brandes JW, Lorenz-Meyer H. Zuckerfreie diat: eine neue perspektive zur behandlung des morbus Crohn? Z Gastroenterol 1981;19:1-12.

19 Levenstein S, Prantera C, Luzi C, D'Ubaldi A. Low residue or normal diet in Crohn's disease: a prospective controlled study in Italian patients. Gut 1985;26:989-93.

20 Rutgeerts P, Geboes K, Vantrappen G, Kerremans R, Coenegrachts JL, Coremans G. Natural history of recurrent Crohn's disease at the ileocolonic anastomosis after curative surgery. Gut 1984;25:665-72.

21 O'Morain C, Segal AW, Levi AJ. Elemental diet as primary treatment of acute Crohn's disease. BrMed f 1984;288:1859-62.

22 Jones VA, Workman E, Freeman AH, Dickinson RJ, Wilson AJ, Hunter JO. Crohn's disease: maintenance of remission by diet. Lancet 1985;ii:177-80.

(Accepted 23 fune 1987)

\section{Corrections}

\section{How much energy does the breast fed infant consume and expend?}

An error occurred in the table in this paper by A Lucas and others ( 11 July, p 75). Some of the $95 \%$ confidence intervals for differences were given in kcal not $\mathrm{MJ}$; these should have read, respectively, -6.8 to $-1.8,-0.06$ to $-0.02,-0.05$ to $0.15,-0.10$ to $0.13,-0.04$ to $0.004,0.13$ to $0.65,0.04$ to $0.07,0.10$ to 0.72 , $-0 \cdot 14$ to $0 \cdot 13,30$ to 172 , and -0.02 to 0.05 .

\section{Radiological progression and lung function in silicosis: a ten year} follow up study

Two errors occurred in this paper by $\mathrm{Ng}$ Tze-Pin and others (18 July, $\mathrm{p} \mathrm{164).} \mathrm{In}$ table $\mathrm{V}$ the regression coefficients for average silica concentration $\left(\mathrm{mg} / \mathrm{m}^{3}\right)$ should both have negative signs, reading -36 (17) for forced expiratory volume in one second and -40 (19) for forced vital capacity. In paragraph 8 , line 12 , of the discussion the figure should read $0 \cdot 10 \mathrm{mg} / \mathrm{m}^{3}$ and not $0.010 \mathrm{mg} / \mathrm{m}^{3}$. 